\title{
Fusobacterium nucleatum infection correlates with two types of microsatellite alterations in colorectal cancer and triggers DNA damage
}

\author{
Yoshiki Okita ${ }^{1 \dagger}$, Minoru Koi $^{1 \dagger}$, Koki Takeda$^{1}$, Ryan Ross ${ }^{2}$, Bhramar Mukherjee ${ }^{2}$, Erika Koeppe ${ }^{1}$, Elena M. Stoffel ${ }^{1}$, \\ Joseph A. Galanko ${ }^{3}$, Amber N. McCoy ${ }^{3}$, Temitope O. Keku33, Yoshinaga Okugawa, Takahito Kitajima4, \\ Yuji Toiyama ${ }^{4}$, Eric Martens ${ }^{5}$ and John M. Carethers ${ }^{1,6^{*}}$ (D)
}

\begin{abstract}
Fusobacterium nucleatum (Fn) is frequently found in colorectal cancers (CRCs). High loads of Fn DNA are detected in CRC tissues with microsatellite instability-high (MSI-H), or with the CpG island hypermethylation phenotype (CIMP). Fn infection is also associated with the inflammatory tumor microenvironment of CRC. A subtype of CRC exhibits inflammation-associated microsatellite alterations (IAMA), which are characterized by microsatellite instability-low (MSI-L) and/or an elevated level of microsatellite alterations at selected tetra-nucleotide repeats (EMAST). Here we describe two independent CRC cohorts in which heavy or moderate loads of Fn DNA are associated with MSI-H and $\mathrm{L} / \mathrm{E} C R C$ respectively. We also show evidence that Fn produces factors that induce $\mathrm{\gamma}-\mathrm{H} 2 \mathrm{AX}$, a hallmark of DNA double strand breaks (DSBs), in the infected cells.
\end{abstract}

Keywords: Fusobacterium nucleatum, Colorectal cancer, Microsatellite instability, CpG island methylator phenotype, MSI-L, EMAST, MSH3, Mismatch repair, Inflammation

\section{Main text}

$F n$ is a common resident in the human gut mucosa and is an anaerobic bacterium that colonizes CRC tumors more frequently than adjacent normal mucosa. To date, most epidemiological studies using 16s rRNA sequencing or metagenomic sequencing methods have detected an increased level of $F n$ DNA and/or RNA in colorectal adenoma/carcinoma tissues or stools from tumor bearing patients, as compared with normal controls [1]. Furthermore, $F n$ infection is associated with specific subtypes of

\footnotetext{
*Correspondence: jcarethe@umich.edu

${ }^{\dagger}$ Yoshiki Okita and Minoru Koi contributed equally to this work

${ }^{1}$ Division of Gastroenterology and Hepatology, Department of Internal Medicine, University of Michigan, Ann Arbor, MI, USA

Full list of author information is available at the end of the article
}

CRC that exhibits CIMP or MSI-H [2, 3]. These observations might suggest that $F n$ infection may contribute to a serrated pathway of CRC development [4]. On the other hand, tumor tissue infected with $F n$ exhibits an inflamed tumor microenvironment, rich in inflammatory factors such as IL6 or reactive oxygen species [5], leading to the assumption that $F n$ infection might also contribute to the generation of IAMA or L/E positive CRC [6-8]. Despite a strong association between $F n$ infection and colorectal cancer, there has been no evidence of $F n$ infection damaging the DNA of colon tissues. In this study, we show evidence that a degree of $F n$ infection may determine molecular characteristics of $\mathrm{CRC}$, and that $F n$ infection may be carcinogenic.

A total of 304 cases of unselected sporadic CRC from North Carolina $[9,10]$ were analyzed for MSI-H, MSI-L 
and EMAST $[11,12]$. The amount of $F n$ DNA per nanogram of tumor tissue DNA was also determined by qPCR (see Additional file 1: Additional Materials and Methods). Thirty-eight cases (12.5\%), 129 cases (42.4\%) and 137 cases (45.1\%) exhibited MSI-H, L/E and MSS, respectively. $F n$ DNA was detected in 116 of 304 (38\%) CRC tumor tissues, ranging from 0.002 to $880 \mathrm{pg} / \mathrm{ng}$ of tissue DNA. When the quantity of $F n$ DNA was compared among MSI-H, L/E and MSS CRC, the Fn DNA load in MSI-H was the highest $(\mathrm{MSI}-\mathrm{H}>\mathrm{L} / \mathrm{E}, \mathrm{p}=0.028$; MSI-H $>$ MSS, $\mathrm{p}=0.000085$ ) and the $F n$ DNA load in L/E was higher than in MSS (L/E $>$ MSS, $p=0.028)($ Fig. 1a). We then determined whether $F n$ infection was associated with MSI-H and/or L/E compared to MSS using a logistic regression model. In univariate analysis, $F n$ infection was associated with MSI-H at an odds ratio (OR) of 4.21 $(\mathrm{p}<0.001)$ and was also associated with $\mathrm{L} / \mathrm{E}$ at an OR of $1.74(\mathrm{p}=0.03)$. When adjusted for sex, age, tumor location and tumor stage, MSI-H $(\mathrm{OR}=3.99,95 \% \mathrm{CI} 1.85-$ 8.9, $\mathrm{p}<0.001)$ and $\mathrm{L} / \mathrm{E}(\mathrm{OR}=1.68,95 \% \mathrm{CI} 1.00-2.84$, $\mathrm{p}=0.05)$ were independently associated with $F n$ infection (Fig. 2). To validate the above results, we analyzed 174 cases of CRC from Mie, Japan. Thirteen (7.4\%), 69, (39.7\%) and 92 cases (52.9\%) exhibited MSI-H, L/E and MSS, respectively. Fn DNA was detected in 131 of 174 (75\%) tumors, ranging from 0.0003 to $200 \mathrm{pg} / \mathrm{ug}$ tissue DNA. The quantity of $F n$ DNA was highest in $\mathrm{MSH}-\mathrm{H}$ compared to L/E $(\mathrm{p}=0.02)$ or MSS $(\mathrm{p}=0.0005)$, and the $F n$ load was higher in L/E than MSS $(\mathrm{p}=0.015)($ Fig. 1b). $F n$ infection was associated with MSI-H at $\mathrm{OR}=13.83$ $(\mathrm{p}=0.007)$ and with $\mathrm{L} / \mathrm{E}$ at $\mathrm{OR}=2.35(\mathrm{p}=0.02)$ in univariate logistic regression analysis. Multivariate analysis adjusted by sex, age. tumor location and stage showed that MSI-H $(\mathrm{OR}=13.67,95 \% \mathrm{CI} 1.63-1789.13, \mathrm{p}=0.01)$ and $\mathrm{L} / \mathrm{E}(\mathrm{OR}=2.23,95 \% \mathrm{CI} 1.05-4.95, \mathrm{p}=0.04)$ were significantly associated with $\mathrm{Fn}$ infection compared to MSS (Fig. 2).

To explore whether $F n$ infection causes cellular DNA damage (see Additional file 1: Additional Materials and Methods), we first determined the ability of human colon cancer cells to support infection. When each of 16 human colon cancer cell lines was co-cultured with $F n$ in 5\% $\mathrm{CO}_{2} / 21 \% \mathrm{O}_{2}$ conditions, $F n$ grew aerobically in 12 of 16 cell lines (Fig. 3a), but not in 4 cell lines (Fig. 3b). Furthermore, there was a difference in the ability to support aerobic growth of $F n$ among the 12 cell lines. Some cell lines such as WIDR required less $F n$ (MOI of 0.001) to initiate successive $F n$ growth whereas SNU503 required $F n$ at MOI of 10 (Fig. 3a). The supernatants from co-cultures between WIDR and $F n$, where $F n$ grew, induced $\gamma$-H2AX in various colon cancer cell lines (Fig. 3c, d), a hallmark of DNA double strand breaks (DSBs) and suggesting that $F n$ infection may be carcinogenic to infected tissues,

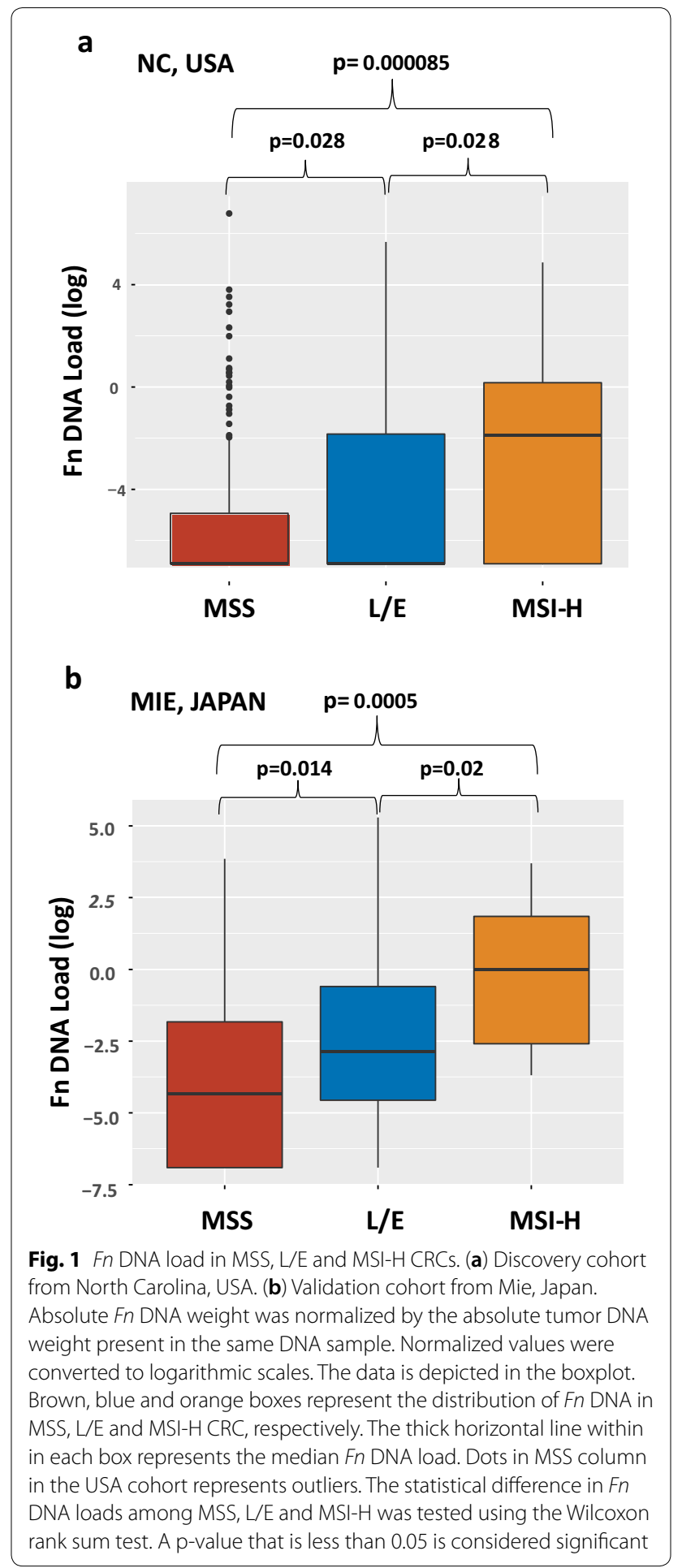

whereas the supernatants from co-cultures between HCEC-1CT and $F n$, where $F n$ growth was not permissive, did not induce $\gamma-\mathrm{H} 2 \mathrm{AX}$ in the exposed colon cancer cell lines (Fig. 3e). Inclusion of the antibiotic metronidazole [13] in co-cultures between WIDR and $F n$ inhibited 


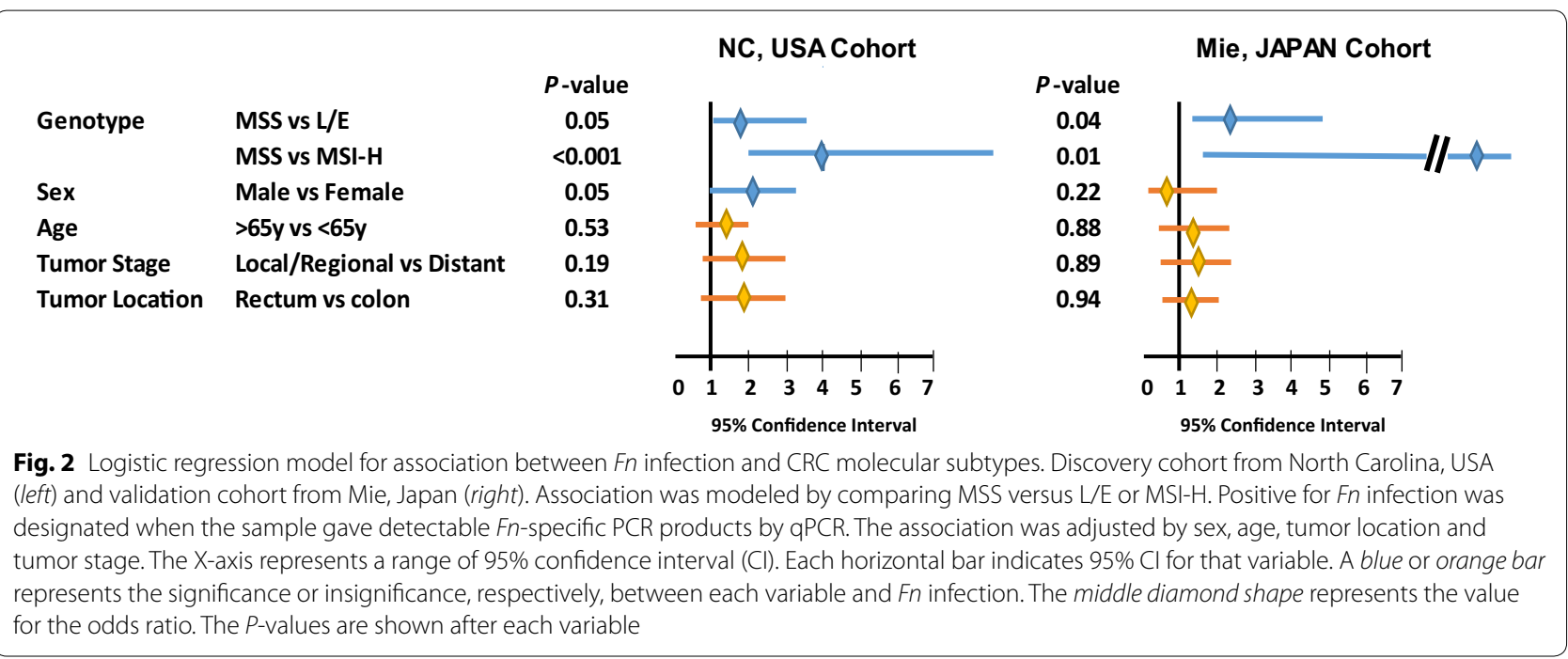

a

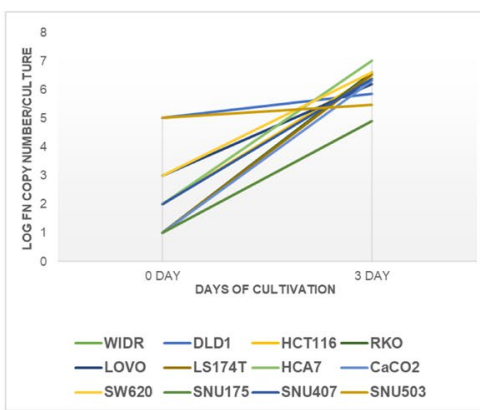

b

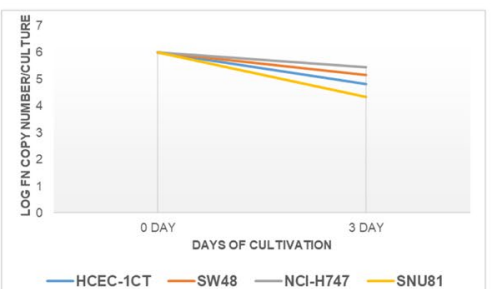

c

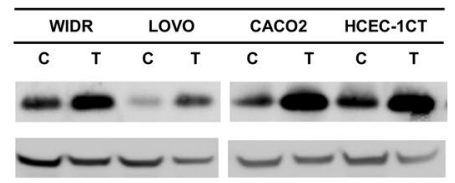

$\gamma-\mathrm{H} 2 \mathrm{AX}$ Tubulin

d

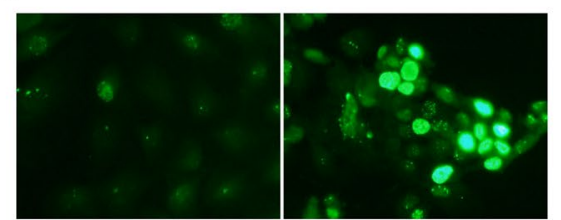

e

Supernatant-treated WIDR

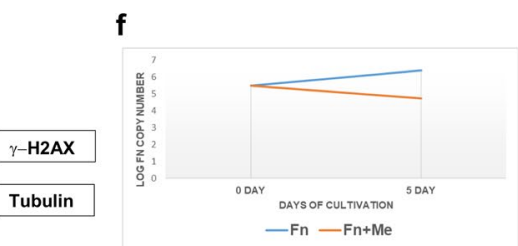

g
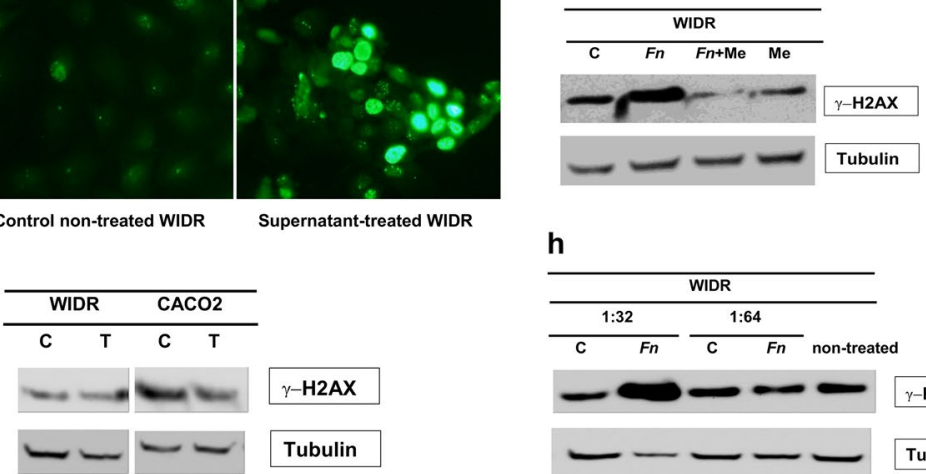

h

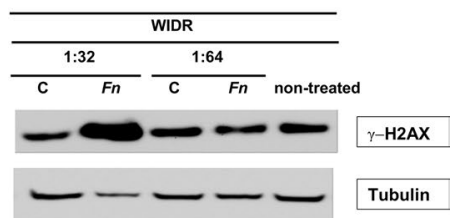

Fig. 3 Aerobic growth of Fn and induction of $\mathrm{y}-\mathrm{H} 2 \mathrm{AX}$ by Fn. (a) Twelve colon cancer cell lines (WIDR, DLD1, HCT116, RKO, LOVO, LS174T, HCA7, $\mathrm{CaCO}_{2}$, SW620, SNU175, SNU407, and SNU503) were infected with Fn strain EAVG_002. During a 3-day incubation, an increase in Fn copy number was observed in co-cultures with these cell lines. (b) No increase in Fn copy number was observed in co-cultures with 4 different colon cancer cell lines (HCEC-1CT, SW48, NCI-H747 and SNU81). X-axis: days of cultivation; Y-axis: log of Fn copy number per culture. (c) WIDR cells were infected with Fn EAVG_002 strain at a multiplicity of infection of 1 under $5 \% \mathrm{CO}_{2} / 21 \% \mathrm{O}_{2}$ for 1 week. Supernatants were collected, centrifuged, and filtered through a $0.2 \mu \mathrm{m}$ porous membrane. $2 \times 10^{5}$ cells (WIDR, LOVO, $\mathrm{CaCO}_{2}$ and HCEC-1CT) were exposed to the supernatants for 9 hr. Cell lysates were analyzed for induction of $\gamma-\mathrm{H} 2 \mathrm{AX}$ by Western blotting using anti- $-\mathrm{H} 2 \mathrm{AX}$ mouse monoclonal antibodies. C: control non-treated; $\mathrm{T}$ : supernatant treated. Treated cells expressed more $\gamma-\mathrm{H} 2 \mathrm{AX}$ than control non-treated cells. (d) Immunofluorescent staining of Fn supernatant-treated WIDR cells with anti- $-\mathrm{H}-\mathrm{H} 2 \mathrm{AX}$ mouse monoclonal antibodies. Brighter nuclear $\mathrm{\gamma}-\mathrm{H} 2 \mathrm{AX}$ signal is evident in treated cells. (e) Supernatant from HCEC-1CT cell culture infected with Fn EAVG_002 strain at an $\mathrm{MOI}$ of 1 under $5 \% \mathrm{CO}_{2} / 21 \% \mathrm{O}_{2}$ conditions failed to induce $\mathrm{\gamma}-\mathrm{H} 2 \mathrm{AX}$ in supernatant-treated WIDR and $\mathrm{CaCO} 2$ cells. C: control non-treated; T: supernatant treated. There was no difference in the amount of $\mathrm{Y}-\mathrm{H} 2 \mathrm{AX}$ between control non-treated and supernatant treated cells. (f) Treatment of co-culture between WIDR and Fn with metronidazole inhibited Fn aerobic growth (red line). Blue line represents growth of Fn without metronidazole. (g) Metronidazole abolished $\mathrm{y}-\mathrm{H} 2 \mathrm{AX}$ induction by Fn. Supernatants were collected from 4 cultures (C: control non-treated cells; Fn: Fn infected cells; Fn + Me: Fn infected cells treated with metronidazole; Me: non-infected cells treated with metronidazole alone) and tested for induction of $\mathrm{Y}-\mathrm{H} 2 \mathrm{AX}$ in WIDR cells. (h) Bacterial medium in which Fn grew anaerobically was tested for $\mathrm{Y}-\mathrm{H} 2 \mathrm{AX}$ induction. The Fn grown medium and control fresh bacterial medium was diluted by Dulbecco's modified Eagle medium with 10\% fetal bovine serum at 1:32 and 1:64 ratio and then exposed to WIDR cells. C: WIDR cells were treated with a diluted fresh bacterial medium; Fn: WIDR cells were treated with diluted Fn grown medium. Induction of $\mathrm{\gamma}-\mathrm{H} 2 \mathrm{AX}$ was detected at 1:32 but not at 1:64 dilutions of Fn grown medium 
$F n$ growth (Fig. 3f) and abolished the supernatants' ability to induce $\gamma-\mathrm{H} 2 \mathrm{AX}$ in WIDR cells (Fig. 3g). Finally, the bacterial culture medium where $F n$ was anaerobically grown induced $\gamma$-H2AX in WIDR cells (Fig. 3h), indicating that $F n$ produces a factor that may cause DNA DSBs in mammalian cells.

Here we provide the initial report showing that heavy or moderate loads of $F n$ DNA are associated with MSI-H and L/E CRC, respectively. We have also identified evidence that $F n$ infection may cause DNA damage in infected colon tissues. It remains to be determined whether different degrees of $F n$ infection directly or indirectly impair DNA mismatch repair differently, resulting in MSI-H or L/E, or whether Fn opportunistically heavily infects MSI-H compared to L/E or MSS CRC. The host cell-dependent aerobic growth of $F n$ observed in this study may give further clues to answer these questions. However, our observation that $F n$ infection may trigger cellular DNA damage strongly suggests that $F n$ infection causes genetic and/or epigenetic alterations, initiating and/or promoting colorectal carcinogenesis. The identity and origin of the DNA damaging factor generated by $F n$ infection will need to be investigated.

\section{Supplementary information}

Supplementary information accompanies this paper at https://doi. org/10.1186/s13099-020-00384-3.

Additional file 1. Additional materials and methods

\section{Abbreviations}

Fn: Fusobacterium nucleatum; CRCs: Colorectal cancers; MSI-H: Microsatellite instability-high; CIMP: CpG island hyper-methylation phenotype; IAMA: Inflammation associated microsatellite alterations; MSI-L: Microsatellite instability-low; EMAST: Elevated level of microsatellite alterations at selected tetra-nucleotide repeats; L/E: MSI-L/EMAST; OR: Odd ratio; DSBs: Double strand breaks; MMR: Mismatch repair; Cl: Confidential interval; MOI: Multiplicity of infection; NC: North Carolina.

\section{Acknowledgements}

Not applicable for this study.

\section{Authors' contributions}

YO, MK, and JMC conceived and designed experiments. YO, MK, and RR performed experiments. BM, EK, EMS, JAG, ANM, TOK, YO, TK, YT, and EM contributed reagents/materials/analysis tools. YO, MK, and JMC wrote and edited the manuscript. All authors read and approved the final manuscript.

\section{Funding}

This study is supported by the United States Public Health Service (NIH grant CA206010) and the A. Alfred Taubman Medical Research Institute of the University of Michigan (to J.M.C.).

\section{Availability of data and materials}

The datasets used and/or analyzed during the current study are available from the corresponding author by reasonable request.

\section{Ethics approval and consent to participate}

The authors are accountable for all aspects of the work in ensuring that questions related to the accuracy or integrity of any part of the work are appropriately investigated and resolved. This retrospective analysis study was conducted according to the World Medical Association Declaration of Helsinki and was approved by the Internal Review Board of the University of North Carolina and Mie University. Since the collection of archival tissue was done through an un-identifiable approach, no consent form was needed for this study. None of the cell lines used in the present study required ethics approval for their use.

\section{Consent for publication}

Not applicable for this study.

\section{Competing interests}

The authors declare that they have no competing interests.

\section{Author details}

${ }^{1}$ Division of Gastroenterology and Hepatology, Department of Internal Medicine, University of Michigan, Ann Arbor, MI, USA. ${ }^{2}$ Department of Biostatistics School of Public Health, University of Michigan, Ann Arbor, MI, USA. ${ }^{3}$ Division of Gastroenterology and Hepatology, Departments of Medicine \& Nutrition, University of North Carolina at Chapel Hill, Chapel Hill, NC, USA. ${ }^{4}$ Department of Gastrointestinal and Pediatric Surgery, Graduate School of Medicine, Mie University, Mie, Japan. ${ }^{5}$ Department of Microbiology and Immunology, University of Michigan, Ann Arbor, MI, USA. ${ }^{6}$ Department of Human Genetics and Rogel Cancer Center, University of Michigan, Ann Arbor, MI, USA.

Received: 30 April 2020 Accepted: 18 September 2020

Published online: 29 September 2020

\section{References}

1. Song M, Chan AT, Sun J. Influence of the gut microbiome, diet, and environment on risk of colorectal cancer. Gastroenterology. 2020;158(2):322-40

2. Tahara T, Yamamoto E, Suzuki H, Maruyama R, Chung W, Garriga J, et al. Fusobacterium in colonic flora and molecular features of colorectal carcinoma. Cancer Res. 2014;74(5):1311-8.

3. Mima K, Cao Y, Chan AT, Qian ZR, Nowak JA, Masugi Y, et al. Fusobacterium nucleatum in colorectal carcinoma tissue according to tumor location. Gut. 2016;65(12):1973-80

4. Yu J, Chen Y, Fu X, Zhou X, Peng Y, Shi L, et al. Invasive Fusobacterium nucleatum may play a role in the carcinogenesis of proximal colon cancer through the serrated neoplasia pathway. Int J Cancer. 2016;139(6):1318-26.

5. Kostic AD, Chun E, Robertson L, Glickman JN, Gallini CA, Michaud M, et al. Fusobacterium nucleatum potentiates intestinal tumorigenesis and modulates the tumor-immune microenvironment. Cell Host Microbe. 2013;14(2):207-15.

6. Koi M, Tseng-Rogenski S, Carethers JM. Inflammation-associated microsatellite alterations: mechanisms and significance in the prognosis of patients with colorectal cancer. World J Gastrointest Oncol. 2018;10(1):1-14.

7. Tseng-Rogenski SS, Hamaya Y, Choi DY, Carethers JM. Interleukin 6 alters localization of hMSH3, leading to DNA mismatch repair defects in colorectal cancer cells. Gastroenterology. 2015;148(3):579-89.

8. Tseng-Rogenski SS, Munakata K, Choi DY, Martin PK, Mehta S, Koi M, Zheng W, Zhang Y, Carethers JM. The human DNA MMR protein $\mathrm{MSH} 3$ contains nuclear localization and export signals that enable nuclear-cytosolic shuttling in response to inflammation. Mol Cell Biol. 2020;40:e00029-e120.

9. Gethings-Behncke C, Coleman HG, Jordao HW, Longley DB, Crawford $\mathrm{N}$, Murray $\sqcup$, et al. Fusobacterium nucleatum in the colorectum, and its association with cancer risk and survival: a systematic review and metaanalysis. Cancer Epidemiol Biomarkers Prev. 2020;29(3):539-48.

10. Devaraj B, Lee A, Cabrera BL, Miyai K, Luo L, Ramamoorthy S, et al. Relationship of EMAST and microsatellite instability among patients with rectal cancer. J Gastrointest Surg. 2010;14(10):1521-8.

11. Munakata K, Koi M, Kitajima T, Tseng-Rogenski S, Uemura M, Matsuno H, et al. Inflammation-associated microsatellite alterations caused by MSH3 dysfunction are prevalent in ulcerative colitis and increase with neoplastic advancement. Clin Transl Gastroenterol. 2019;10(12):e00105. 
12. Raeker MO, Pierre-Charles J, Carethers JM. Tetranucleotide microsatellite mutational behavior assess in real time: implications for future microsatellite panels. Cell Mol Gastroenterol Hepatol. 2020;9:689-704.

13. Bullman S, Pedamallu CS, Sicinska E, Clancy TE, Zhang X, Cai D, et al.

Analysis of Fusobacterium persistence and antibiotic response in colorectal cancer. Science. 2017;358(6369):1443-8.

\section{Publisher's Note}

Springer Nature remains neutral with regard to jurisdictional claims in published maps and institutional affiliations.
Ready to submit your research? Choose BMC and benefit from:

- fast, convenient online submission

- thorough peer review by experienced researchers in your field

- rapid publication on acceptance

- support for research data, including large and complex data types

- gold Open Access which fosters wider collaboration and increased citations

- maximum visibility for your research: over $100 \mathrm{M}$ website views per year

At BMC, research is always in progress.

Learn more biomedcentral.com/submissions 